\title{
ANÁLISE DO DESEMPENHO DOS ARRANJOS FÍSICOS DISTRIBUÍDOS OPERANDO SOB ROTEAMENTO DE PEÇAS COM FLEXIBILIDADE DE SEQÜENCIAMENTO
}

\author{
PERFORMANCE ANALYSIS OF THE DISTRIBUTED LAYOUT \\ OPERATING UNDER PART ROUNTIG WITH SEQUENCE FLEXIBILITY
}

\author{
José Hamilton Chaves Gorgulho Júnior ${ }^{1}$; Eduardo Vila Gonçalves Filho ${ }^{2}$ \\ ${ }^{1}$ Universidade Federal de Itajubá - UNIFEI - Itajubá - Brasil gorgulhojunior@,ig.com.br \\ ${ }^{2}$ Escola de Engenharia de São Carlos - EESC - São Carlos - Brasil evila@sp.usp.br
}

\begin{abstract}
Resumo
A literatura que trata dos arranjos físicos distribuídos sugere que raramente a desagregação completa dos departamentos é justificada. Porém, a abordagem usada neste artigo usa dados mais condizentes com a realidade do ambiente de manufatura para o qual esse tipo de distribuição de máquinas é indicado e os resultados mostram um sensivel ganho de desempenho na adoção do arranjo físico maximamente distribuído. O artigo inicia apresentando o arranjo físico distribuído e, em seguida, destaca os objetivos do trabalho. Em seguida descreve-se a forma de roteamento adotada na simulação e a geração dos dados de entrada (arranjos físicos e peças). Na seqüência os dados obtidos são mostrados e comentados. O artigo encerra-se com os comentários e conclusões sobre os resultados das simulações.
\end{abstract}

Palavras-chave: arranjo físico distribuído, simulação, roteamento.

\section{Introdução}

Alguns setores da indústria de manufatura atual estão inseridos em um ambiente onde as mudanças nos processos e produtos ocorrem com grande freqüência. Volátil, turbulento ou altamente dinâmico são os termos usados por Rheault, Drolet e Abdulnour (1995) para definir esses ambientes que são caracterizados por:

- Alta variabilidade na demanda;

- Alta variabilidade no tamanho dos lotes de produção;

- Alta variabilidade nos tempos de processamento e nos tempos de preparação;

- Demanda parcialmente ou totalmente estocástica;

- Freqüentes mudanças no mix de produtos; 
- Variabilidade nas seqüências de produção;

- Forte competição.

Segundo Benjaafar, Heragu e Irani (2002) os arranjos físicos clássicos (por produto, por processo, posicional e celular) não atingem um nível de desempenho satisfatório nesses ambientes e, dessa forma, novas distribuições foram propostas: arranjo físico distribuído (MONTREUIL e VENKATADRI, 1991), arranjo físico fractal (VENKATADRI, RARDIN e MONTREUIL, 1997) e arranjo físico modular (IRANI e HUANG, 2000).

O arranjo físico distribuído (distributed layout) caracteriza-se por espalhar as máquinas pelo chão de fábrica de modo a aproximar equipamentos de diferentes tipos. Em outras palavras o objetivo desse arranjo físico é garantir a proximidade de qualquer estação de trabalho de qualquer processo com estações de trabalho de outros processos para que rotas mais eficientes possam ser criadas pelo sistema de planejamento e controle da manufatura.

O trabalho de Montreuil et al. (1993) faz uma comparação de desempenho entre arranjos físicos aleatoriamente distribuídos com arranjos físicos cuja distribuição foi realizada por um critério de utilização de máquinas. Benjaafar e Sheikhzadeh (2000) e Lahmar e Benjaafar (2001, 2002a, 2002b e 2005) realizaram comparações entre arranjos físicos funcionais, aleatoriamente distribuídos, parcialmente distribuídos e maximamente distribuídos. Os resultados desses trabalhos apontam para uma grande superioridade do arranjo físico parcialmente distribuído sobre o funcional e uma pequena vantagem do arranjo físico maximamente distribuído sobre o parcialmente distribuído.

Nesses trabalhos, e também nas demais pesquisas relacionadas com o arranjo físico distribuído, os resultados foram obtidos por meio de simulações com dados gerados pelos autores, sendo que a única exceção encontrada foi o trabalho de Baykasoglu (2003) que usou dados reais, mas sem implementar o arranjo físico projetado. Nenhuma pesquisa levou em consideração peças com flexibilidade no seqüenciamento das operações, permitindo levantar a hipótese de que o arranjo físico maximamente distribuído possa ter um desempenho sensivelmente superior aos demais se o sistema de programação tiver opções de roteamento.

\section{Objetivos}

O objetivo deste trabalho é avaliar o desempenho dos arranjos físicos distribuídos quando o roteamento das tarefas tem à sua disposição processos de fabricação com flexibilidade de seqüenciamento. A estratégia adotada foi simular o roteamento de conjuntos de peças em grupos de arranjos físicos e obter a distância total percorrida por todas as peças. 
O roteamento das peças foi realizado de duas formas. Em uma delas usou-se apenas a primeira seqüência de fabricação permitida para cada peça (roteamento rígido) enquanto a outra forma explora todas as possíveis seqüências (roteamento flexível). Nas duas formas, para cada seqüência, analisa-se heuristicamente as possíveis rotas para encontrar aquela que minimiza duas variáveis: o tempo necessário para completar a peça e a distância total percorrida no chão de fábrica.

\section{Roteamento}

As possíveis rotas para uma determinada seqüência de fabricação dependem do número de operações e do número de máquinas que podem executar cada operação. A combinação destes elementos forma uma árvore de busca, como mostra a Figura 1. Neste exemplo tem-se uma peça com 4 operações na seguinte ordem de processos: 1-2-3-4. Considerando que o processo 1 possui uma máquina (1.1), o processo 2 duas máquinas (2.1 e 2.2) e os processos 3 e 4 possuem três máquinas cada um $(3.1,3.2,3.3,4.1,4.2$ e 4.3) conclui-se que há 18 rotas possíveis.

\section{Figura 1 - Arranjo físico e árvore de rotas}

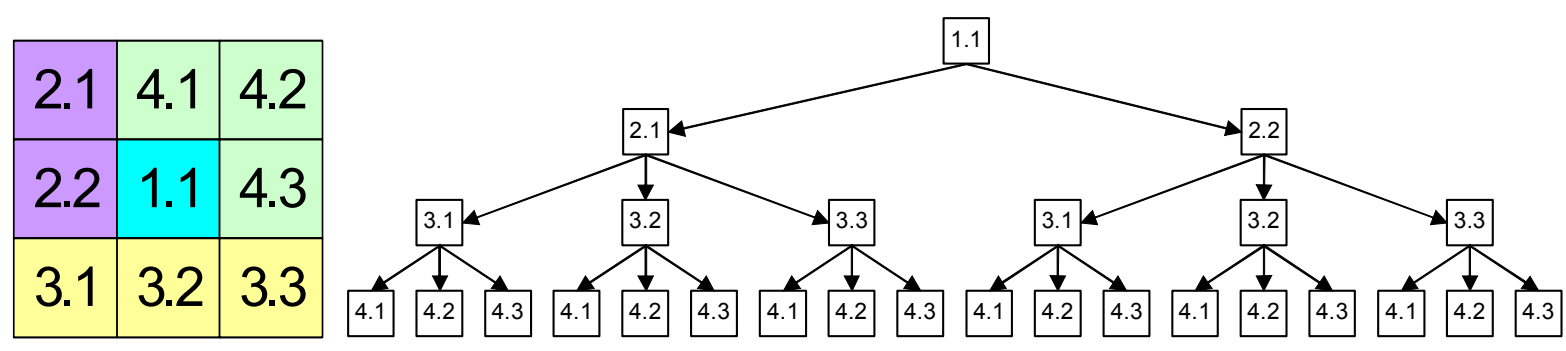

Ao invés de calcular as distâncias e tempos para todas as possíveis rotas é melhor usar uma heurística que reduza a quantidade de cálculos e, conseqüentemente, o tempo computacional consumido nessa tarefa. Essa heurística pode ser descrita como: analisar cada par de operações e estender a busca apenas aos nós de menor distância (nós mais promissores).

O roteamento da primeira peça leva em consideração apenas as distâncias entre as máquinas pois ainda não há nenhuma operação alocada. Já, para as demais peças, além de analisar a distância, é necessário verificar em cada máquina os instantes de tempo que estão livres para alocação e escolher aquele que permita encerrar a peça o mais cedo possível.

A Figura 2 mostra dois gráficos de Gantt. O gráfico da esquerda mostra o roteamento da peça na ordem de operações citada (1-2-3-4). O gráfico da direita mostra o roteamento da mesma peça supondo que as operações possam ocorrer em qualquer ordem (flexibilidade completa). Neste 
caso há 24 possíveis seqüências (4!) que levam a um total de 432 rotas (18 rotas para cada seqüência) e a seqüência adotada foi 2-1-4-3.

Figura 2 - Gráficos de Gantt
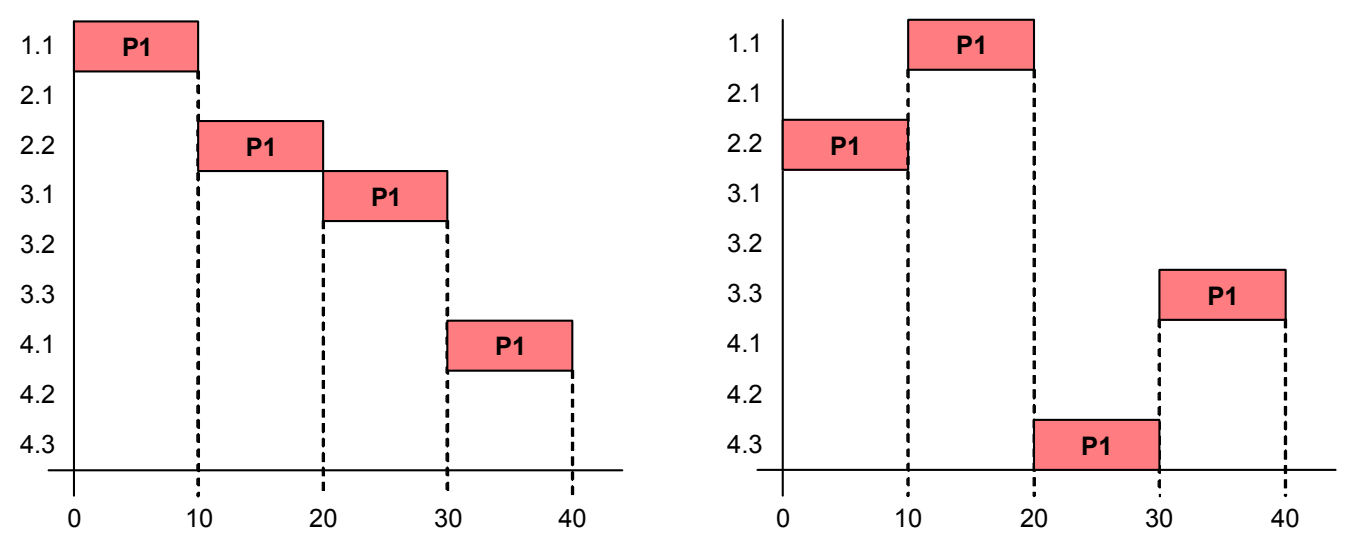

Apesar dos dois roteamentos concluírem a peça no mesmo instante a da esquerda percorre 5 unidades de distância retilinear enquanto que a da direita percorre apenas 3.

\section{Estudos de caso}

\subsection{Os arranjos físicos}

Um dos dados de entrada para a simulação são os arranjos físicos. Foram automaticamente elaborados 152, sendo: 50 funcionais, 50 parcialmente distribuídos (2 departamentos para cada processo), 50 aleatoriamente distribuídos e 2 maximamente distribuídos. Os arranjos físicos possuem 40 máquinas distribuídas em 15 processos, da forma apresentada por Montreuil e Venkatadri (1991) e ilustrada na Figura 3 (5 linhas e 8 colunas) sendo:

- Processos 1 até 5: 1 máquina para cada processo;

- Processo 6 até 10: 2 máquinas para cada processo;

- Processo 11:3 máquinas;

- Processo 12: 4 máquinas;

- Processo 13: 5 máquinas;

- Processo 14: 6 máquinas;

- Processo 15: 7 máquinas.

Um dos arranjos maximamente distribuídos foi elaborado usando o algoritmo denominado ALVO proposto por Gorgulho Júnior e Gonçalves Filho (2005a). O outro foi obtido por meio de um 
algoritmo genético que maximiza a distribuição das máquinas pela minimização do grau de distribuição, que é um índice proposto por Benjaafar e Sheikhzadeh (2000).

Figura 3 - Arranjos físicos maximamente distribuídos: algoritmo ALVO (esquerda) e algoritmo genético

\begin{tabular}{|l|l|l|l|l|l|l|l|}
\hline 14.1 & 13.2 & 15.3 & 11.1 & 14.3 & 15.7 & 13.4 & 14.5 \\
\hline 15.1 & 9.1 & 12.1 & 4.1 & 7.1 & 15.5 & 8.2 & 12.3 \\
\hline 10.1 & 6.1 & 3.1 & 1.1 & 2.1 & 13.1 & 6.2 & 10.2 \\
\hline 12.2 & 8.1 & 11.3 & 5.1 & 7.2 & 12.4 & 9.2 & 11.2 \\
\hline 14.2 & 13.3 & 15.2 & 14.4 & 15.4 & 15.6 & 13.5 & 14.6 \\
\hline
\end{tabular}

\begin{tabular}{|l|l|l|l|l|l|l|l|}
\hline 15.1 & 15.3 & 12.1 & 14.1 & 13.2 & 15.5 & 14.4 & 15.7 \\
\hline 14.6 & 9.1 & 10.1 & 11.1 & 7.1 & 8.2 & 12.3 & 14.5 \\
\hline 13.4 & 6.1 & 5.1 & 1.1 & 2.1 & 9.2 & 10.2 & 13.1 \\
\hline 12.2 & 7.2 & 8.1 & 3.1 & 4.1 & 6.2 & 11.2 & 15.4 \\
\hline 14.3 & 11.3 & 15.2 & 13.3 & 12.4 & 14.2 & 13.5 & 15.6 \\
\hline
\end{tabular}

\subsection{Peças}

O outro dado de entrada para a simulação são as peças. Foram elaborados 10 conjuntos de 150 peças geradas automaticamente seguindo o procedimento proposto por Gorgulho Júnior e Gonçalves Filho (2005b). Cada peça foi elaborada para ter entre 3 e 10 operações cujos processos foram selecionados aleatoriamente entre os 15 disponíveis nos arranjos físicos. A duração de cada operação foi aleatoriamente escolhida entre 10 e 100 unidades de tempo. Para cada número de operações há diferentes modelos de relações de precedência que também foram escolhidos aleatoriamente. Cada modelo de precedência leva a diferentes números de seqüências de fabricação. Como exemplo, a Figura 4 mostra duas peças do primeiro conjunto gerado, sendo que a peça 003 usou o primeiro modelo para peças com 4 operações ( 2 possíveis seqüências) enquanto a peça 026 usou o terceiro modelo para peças com 10 operações (96 possíveis seqüências). Nessa figura os valores abaixo das operações indicam a sua duração.

Figura 4 - Relações de precedência das peças 003 (esquerda) e 026 (direita) do conjunto de peças 1
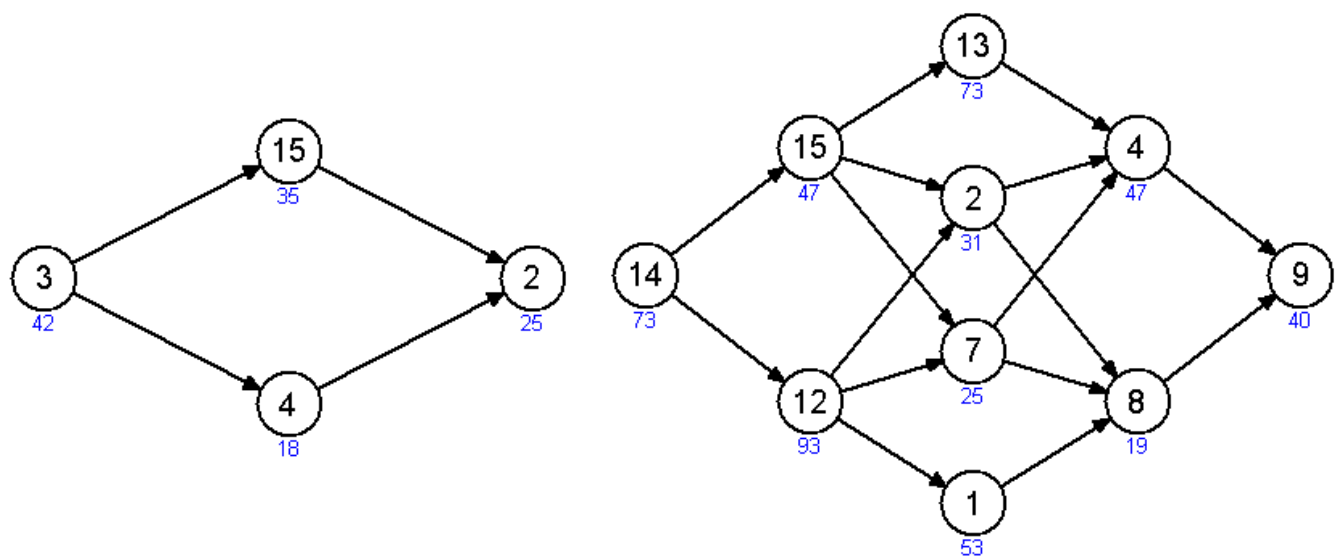
O procedimento de geração automática dos conjuntos de peças foi elaborado para levar em consideração a proporção do número de máquinas existentes em cada processo. Esse cuidado evitou que os processos com poucas máquinas fossem utilizados por muitas peças, aproximando a simulação da realidade onde procura-se evitar a geração de gargalos.

\subsection{Simulações}

Foi usado um microcomputador com processador Athlon XP 2600+ operando em $2.08 \mathrm{GHz}$ e com $1 \mathrm{~Gb}$ de memória RAM em plataforma Windows XP Professional. O software de roteamento foi implementado em Visual Basic 6. O tempo médio para realizar o roteamento de cada conjunto de 150 peças em cada grupo de 50 arranjos físicos foi de 45 segundos no roteamento rígido e 15 minutos no roteamento flexível.

\subsection{Resultados}

A Tabela 1 apresenta as médias das distancias totais obtidas no roteamento rígido dos 10 conjuntos de peças em cada um dos conjuntos de arranjos físicos. Os resultados para os arranjos físicos maximamente distribuídos pelos algoritmos ALVO e genético não são médias pois há apenas um representante de cada distribuição. A parte inferior da Tabela 1 mostra as estatísticas calculadas a partir dos valores obtidos para os 10 conjuntos de peças. A Tabela 2 apresenta os mesmos dados para o roteamento flexível.

Tabela 1 - Resultados do roteamento rígido nos arranjos físicos

\begin{tabular}{|c|c|c|c|c|c|c|}
\hline & & Funcional & Parcialmente & Aleatoriamente & ALVO & $\mathbf{A G}$ \\
\hline \multirow{10}{*}{ 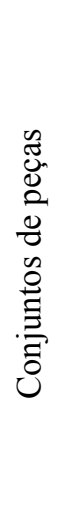 } & 1 & 3586.96 & 3270.04 & 3023.82 & 2602 & 2538 \\
\hline & 2 & 3497.66 & 3214.58 & 2965.98 & 2572 & 2541 \\
\hline & 3 & 3637.18 & 3340.16 & 3080.28 & 2637 & 2574 \\
\hline & 4 & 3381.94 & 3094.96 & 2852.16 & 2507 & 2394 \\
\hline & 5 & 3547.06 & 3271.56 & 3017.44 & 2602 & 2583 \\
\hline & 6 & 3589.32 & 3294.58 & 3058.14 & 2803 & 2597 \\
\hline & 7 & 3571.72 & 3256.46 & 3015.12 & 2544 & 2509 \\
\hline & 8 & 3388.54 & 3105.32 & 2861.00 & 2516 & 2485 \\
\hline & 9 & 3530.88 & 3246.74 & 2999.46 & 2515 & 2490 \\
\hline & 10 & 3392.76 & 3102.18 & 2870.48 & 2546 & 2444 \\
\hline \multirow{5}{*}{ 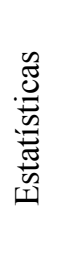 } & Média & 3512.402 & 3219.658 & 2974.388 & 2584.4 & 2515.5 \\
\hline & Mínimo & 3381.94 & 3094.96 & 2852.16 & 2507 & 2394 \\
\hline & Máximo & 3637.18 & 3340.16 & 3080.28 & 2803 & 2597 \\
\hline & Amplitude & 255.24 & 245.2 & 228.12 & 296 & 203 \\
\hline & D. Padrão & 93.690 & 88.131 & 83.982 & 88.140 & 64.355 \\
\hline
\end{tabular}


Tabela 2 - Resultados do roteamento flexível nos arranjos físicos

\begin{tabular}{|c|c|c|c|c|c|c|}
\hline & & Funcional & Parcialmente & Aleatoriamente & ALVO & $\mathbf{A G}$ \\
\hline \multirow{10}{*}{ 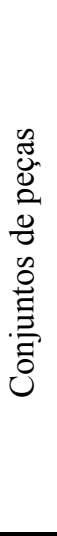 } & 1 & 3141.04 & 2851.66 & 2660.68 & 2302 & 2121 \\
\hline & 2 & 3053.12 & 2790.04 & 2560.22 & 2222 & 2087 \\
\hline & 3 & 3210.46 & 2935.44 & 2716.76 & 2379 & 2321 \\
\hline & 4 & 2962.36 & 2694.60 & 2483.90 & 2095 & 2138 \\
\hline & 5 & 3072.54 & 2813.08 & 2595.76 & 2235 & 2169 \\
\hline & 6 & 3103.70 & 2828.28 & 2617.74 & 2251 & 2218 \\
\hline & 7 & 3091.72 & 2826.92 & 2606.82 & 2205 & 2214 \\
\hline & 8 & 2962.96 & 2712.44 & 2511.96 & 2157 & 2078 \\
\hline & 9 & 3058.34 & 2777.18 & 2575.58 & 2182 & 2090 \\
\hline & 10 & 2955.28 & 2690.24 & 2507.76 & 2158 & 2108 \\
\hline \multirow{5}{*}{ 苞 } & Média & 3061.152 & 2791.988 & 2583.718 & 2218.6 & 2154.4 \\
\hline & Mínimo & 2955.28 & 2690.24 & 2483.9 & 2095 & 2078 \\
\hline & Máximo & 3210.46 & 2935.44 & 2716.76 & 2379 & 2321 \\
\hline & Amplitude & 255.18 & 245.2 & 232.86 & 284 & 243 \\
\hline & D. Padrão & 83.155 & 77.107 & 72.234 & 80.473 & 77.194 \\
\hline
\end{tabular}

\section{Análises}

$\mathrm{Na}$ Tabela 3 estão apresentadas as diferenças percentuais entre as distâncias percorridas em cada tipo de arranjo físico no modo de roteamento rígido. Os valores indicam a melhoria percentual do índice, ou seja, a redução na distância percorrida. Os valores da Tabela 4 mostram que a melhoria percentual no roteamento flexível tem a mesma ordem de grandeza do roteamento rígido, apesar dos valores absolutos diferirem.

Tabela 3 - Diferenças percentuais no roteamento rígido

\begin{tabular}{llcccc}
\hline & & \multicolumn{4}{c}{ Para o arranjo físico } \\
\hline & & Parcialmente & Aleatoriamente & ALVO & AG \\
\hline \multirow{5}{*}{ Do arranjo físico } & Parcialmente & 8.3346 & 15.3176 & 26.4206 & 28.3823 \\
& Aleatoriamente & - & 7.6179 & 19.7306 & 21.8706 \\
& ALVO & - & - & 13.1115 & 15.4280 \\
& ALV & - & - & - & 2.6660 \\
\hline
\end{tabular}

Tabela 4 - Diferenças percentuais no roteamento flexível

\begin{tabular}{llcccc}
\hline & & \multicolumn{4}{c}{ Para o arranjo físico } \\
\hline & & Parcialmente & Aleatoriamente & ALVO & AG \\
\hline \multirow{5}{*}{ Do arranjo físico } & Funcional & 8.7929 & 15.5965 & 27.5240 & 29.6213 \\
& Parcialmente & - & 7.4596 & 20.5369 & 22.8363 \\
& Aleatoriamente & - & - & 14.1315 & 16.6163 \\
& ALVO & - & - & - & 2.8937 \\
\hline
\end{tabular}


A Tabela 5 compara a média rígida com a média do roteamento flexível de cada tipo de arranjo físico. Pode-se concluir que o roteamento flexível reduz a distância percorrida pelas peças em $13.6 \%$ aproximadamente.

Tabela 5 - Redução percentual na distância total percorrida entre o roteamento rígido e o flexível

\begin{tabular}{cccccc}
\hline & Funcional & Parcialmente & Aleatoriamente & ALVO & AG \\
\hline Média do roteamento rígido & 3512.402 & 3219.658 & 2974.388 & 2584.4 & 2515.5 \\
Média do roteamento flexível & 3061.152 & 2791.988 & 2583.718 & 2218.6 & 2154.4 \\
\hline Redução percentual & 12.8473 & 13.2831 & 13.1345 & 14.1542 & 14.3550 \\
\hline
\end{tabular}

Além das distâncias totais percorridas o simulador também apresenta o tempo total consumido pelas peças. No roteamento rígido a maior diferença obtida foi de $0.51 \%$ enquanto que no roteamento flexível foi de $0.47 \%$. Esses valores mostram que a disposição das máquinas praticamente não tem influência no makespan, como era de se esperar, já que essa variável é otimizada por meio da alteração da ordem de entrada das peças no sistema (scheduling). Porém, comparando o resultado médio dos dois modos de roteamento nota-se que o roteamento flexível leva a uma redução de cerca de $5.8 \%$ no tempo total. Isso se deve ao fato do procedimento analisar todas as possíveis seqüências de cada peça permitindo encontrar alocações que aproveitem melhor os tempos livres entre as operações já alocadas.

\section{Conclusões}

O roteamento flexível mostrou-se vantajoso, independente do tipo de arranjo físico adotado, conseguindo, em média, reduzir o tempo total de conclusão das peças em $5.8 \%$ e reduzindo a distância total percorrida em 13,6\%. Em termos de desempenho os arranjos físicos estão na seguinte ordem (do pior para o melhor): funcional, parcialmente distribuído, aleatoriamente distribuído e maximamente distribuído.

Os dados obtidos nas simulações mostraram que o arranjo físico maximamente distribuído tem um desempenho sensivelmente superior ao demais tanto no roteamento rígido quanto no flexível, levando a concluir que a desagregação completa dos departamentos é altamente vantajosa. Essa constatação vai de encontro com as conclusões apresentadas por Benjaafar e Sheikhzadeh (2000) e Lahmar e Benjaafar (2001, 2002a, 2002b e 2005) que indicam que a desagregação completa não se justifica pois a maior parte dos benefícios seriam obtidos quando os departamentos são divididos em duas partes. 
Essa disparidade de resultados deve-se à forma de modelagem do problema e ao próprio objetivo a ser atingido. O objetivo desses pesquisadores era projetar um arranjo físico distribuído que atendesse a vários períodos permitindo, inclusive, uma reorganização das estações de trabalho ao final de cada período. Além disso a modelagem baseou-se em probabilidades para definir possíveis cenários e níveis de demanda (detalhes relativos à modelagem estão em Benjaafar (1995) e Benjaafar e Sheikhzadeh (1996)). Também é importante mencionar que esses autores assumem que as informações relativas às demandas de cada período estão disponíveis no estágio inicial do projeto. Porém, segundo Baykasoglu (2003), a obtenção de informações futuras e o uso de probabilidades em um ambiente altamente volátil não se mostram como abordagens adequadas.

Os resultados desta pesquisa reforçam a opinião de Baykasoglu (2003). Em ambientes altamente dinâmicos não é interessante consumir esforços no projeto do arranjo físico tentando encontrar relações entre os pedidos, que acabam apontando para mudanças periódicas na disposição das máquinas. Ao invés disso, adotando o arranjo físico maximamente distribuído, os esforços são direcionados na programação e no roteamento das peças, tirando o máximo proveito da proximidade de estações de trabalho de diferentes tipos.

A diferença média de $2.7 \%$ entre os dois arranjos físicos maximamente distribuídos permite concluir que para configurações com poucas máquinas, o custo computacional do algoritmo genético é aceitável. Enquanto o algoritmo ALVO consumiu 0.02 segundos para gerar a distribuição das máquinas o algoritmo genético gastou 50 minutos como mostra a Figura 5. Porém, com o aumento do número de máquinas há um crescimento muito grande no tempo de cálculo do grau de distribuição, tornando impraticável sua aplicação e deixando o algoritmo ALVO como sendo a única opção viável no momento.

Figura 5 - Evolução do grau de distribuição no algoritmo genético

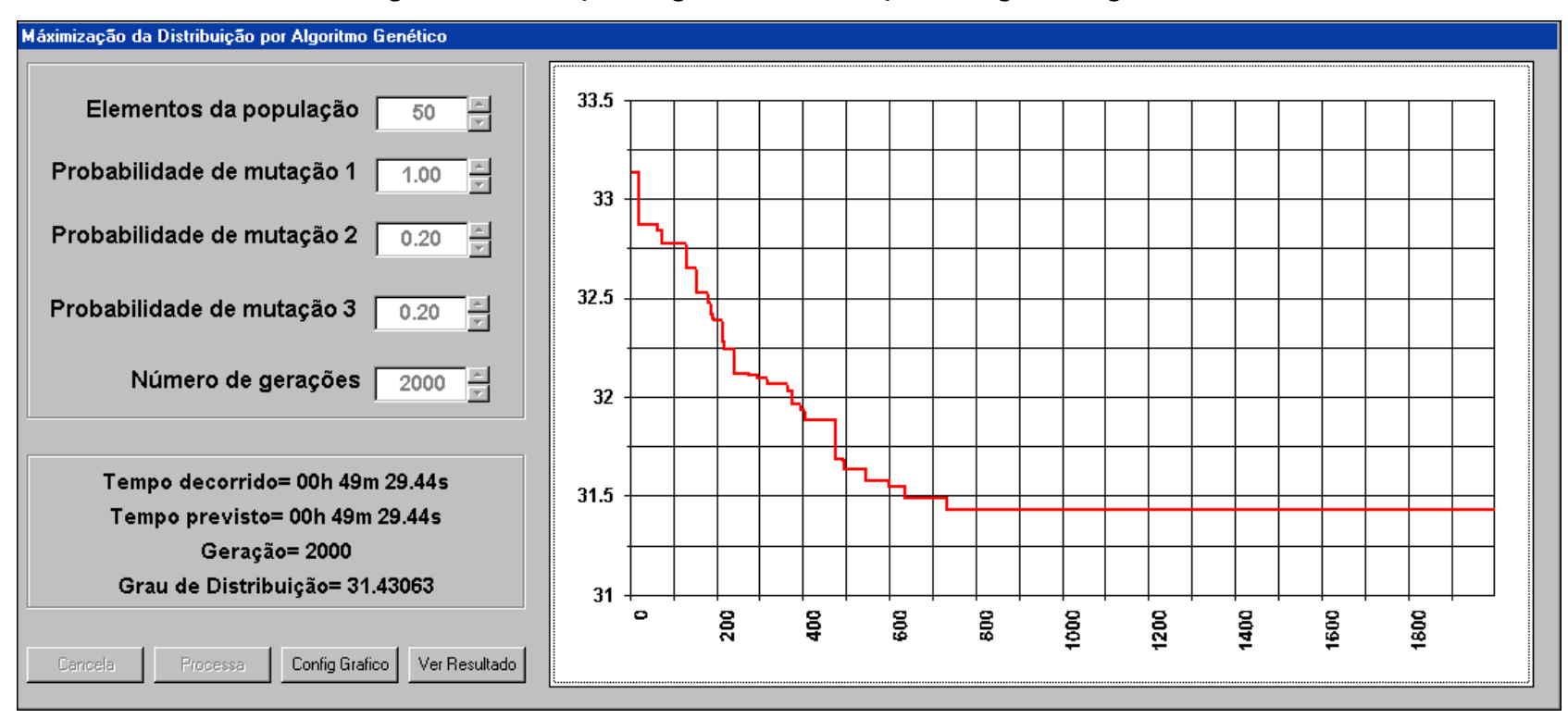


É importante lembrar que devido à grande aleatoriedade envolvida no processamento de um algoritmo genético é comum atingir um ótimo local a partir do qual torna-se extremamente difícil sair para atingir o ótimo global. Sendo assim, quando utiliza-se um algoritmo genético, torna-se necessário executá-lo algumas vezes para tentar atingir o valor ótimo. Sendo assim, o tempo de processamento consumido acaba sendo relativamente elevado, mesmo para arranjos físicos médios.

\title{
7. Comentários finais
}

O procedimento de roteamento usado nas simulações analisa todas as seqüências de fabricação permitidas pelo diagrama de precedência de cada peça. Para cada uma dessas seqüências realiza-se uma busca pela rota que permita a conclusão da peça no menor tempo e percorrendo a menor distância.

Os resultados obtidos comprovam a afirmação de Montreuil et al. (1993) que declararam que o sucesso do arranjo físico distribuído depende fortemente do sistema de planejamento e controle da produção e de Askin, Ciarallo e Lundgren (1999) que afirmaram que os avanços na tecnologia da informação fariam possível ter um sistema de controle em tempo real para definir uma tarefa à melhor máquina.

Futuras pesquisas deverão avaliar se os mesmos níveis de desempenho são obtidos em arranjos físicos de diferentes tamanhos e também com departamentos equilibrados (mesmo número de máquinas). Além disso é necessário avaliar o arranjo físico distribuído com diferentes graus de desagregação dos departamentos. Outra frente de pesquisa relaciona-se com a análise de diferentes regras de prioridade das peças, ordenando-as segundo a duração das operações, por exemplo.

Também parece ser possível melhorar o desempenho do algoritmo genético elaborado alterando-se a estratégia de varredura da matriz que representa o arranjo físico e que leva ao cálculo do grau de distribuição. Outra opção é implementar o algoritmo genético usando a linguagem de programação $\mathrm{C}++$ que, reconhecidamente, cria arquivos executáveis muito mais rápidos que aqueles obtidos pela compilação do Visual Basic.

\begin{abstract}
The literature about distributed layout suggests that full department disaggregation and distribution would rarely be justified. However, the approach in this paper show a sensible performance improves when the distributed layout is adopted. The paper show the distributed layout, describe the routing mode adopted in the simulation, generation of data input (layouts and parts), obtained data and conclusions.
\end{abstract}

Key-words: distributed layout, simulation, routing. 


\section{Referências}

ASKIN, R. G.; CIARALLO, F. W.; LUNDGREN, N. H. (1999). An empirical evaluation of holonic and fractal layouts. International Journal of Production Research, v. 37, n. 5, p. 961-978.

cross ref

BAYKASOGLU, A. Capability-based distributed layout approach for virtual manufacturing cells. International Journal of Production Research, v.41, n.11, p.2597-2618, 2003.

cross ref

BENJAAFAR, S. Design of flexible layouts for manufacturing systems. IEEE - Engineering Management Conference, p.421-427, 1995.

BENJAAFAR, S.; HERAGU, S. S.; IRANI, S. A. Next Generation Factory Layouts: Research Challenges and Recent Progress. Interfaces, v.32, n.6, Nov-Dec, p.58-76, 2002.

cross ref

BENJAAFAR, S.; SHEIKHZADEH, M. Design of flexible layouts for manufacturing systems. Proceedings of de IEEE, International Conference on Robotics and Automation, Minneapolis, Minnesota, Apr., p.852-857, 1996.

BENJAAFAR, S.; SHEIKHZADEH, M. Design of flexible plant layouts. IIE Transactions, v.32, n.4, p.309-322, 2000. crossef

GORGULHO JÚNIOR, J. H. C.; GONÇALVES FILHO, E. V. Nova abordagem na geração de arranjo físico maximamente distribuído. XII SIMPEP - Bauru, SP, Brasil, 07 a 09 Nov, 2005a.

GORGULHO JÚNIOR, J. H. C.; GONÇALVES FILHO, E. V. Uma solução computacional para geração automática de peças com flexibilidade de processo para simulação. XII SIMPEP - Bauru, SP, Brasil, 07 a 09 Nov. $2005 b$.

IRANI, S. A.; HUANG, H. Custom design of facility layouts for multi-product facilities using layout modules. IEEE Transactions. Robotics Automation, v.16, p.259-267, 2000.

crossef

LAHMAR, M.; BENJAAFAR, S. Design of dynamic distributed layouts. INFORMS Fall Meeting, Session TC17 (Advances in Factory Layouts), Nov., Miami, Fl, 2001.

LAHMAR, M.; BENJAAFAR, S. Design of dynamic distributed layouts. Working Paper, Department of Mechanical Engineering, University of Minnesota, Minneapolis, MN, 2002a.

LAHMAR, M.; BENJAAFAR, S. Design of dynamic distributed layouts. Proceedings of the 11th Annual Industrial Engineering Research Conference (IERC), May 19-21, Orlando, Fl, 2002 b.

LAHMAR, M.; BENJAAFAR, S. Design of distributed layouts. IIE Transactions, v.37, p.303-318, 2005.

cross ${ }^{\text {ref }}$

MONTREUIL, B.; VENKATADRI, U. Scattered layout of intelligent job shops operating in a volatile environments. Proceedings of the International Conference on Computer Integrated Manufacturing, Singapore, p.295298, 1991.

MONTREUIL, B.; LEFRANÇOIS, P.; MARCOTTE, S.; VENKATADRI, U. Layout for chaos - Holographic layout of manufacturing systems operating in highly volatile environments. Document de Travail 93-53, Groupe de Recherche en Gestion de La Logistique, Faculté des Sciences de L'Administration, Université Laval, Québec, Canada, 1993.

RHEAUlT, M; DROLET, J. R.; ABDULNOR, G. Physically reconfigurable virtual cells: A dynamic model for a highly dynamic environment. Computers and Industrial Engineering, v.29, n.1-4, p.221-225, 1995.

cross ref 
VENKATADRI, U; RARDIN, R. L.; MONTREUIL, B. A design methodology for the fractal layout organization. IEE Transactions., v.29, n.10, p.911-924, 1997.

cross ${ }^{\text {ref }}$

\section{Dados dos autores:}

Nome completo: José Hamilton Chaves Gorgulho Júnior

Filiação institucional: Universidade Federal de Itajubá (UNIFEI)

Departamento: Instituto de Engenharia de Produção e Gestão (IEPG)

Função ou cargo ocupado: Professor

Endereço completo para correspondência: Av. BPS, 1303 - Bairro Pinheirinho, Itajubá, MG, Brasil, CEP: $37.500-903$.

Telefones para contato: (035) 3622-3563

e-mail: gorgulhojunior@ig.com.br

Nome completo: Eduardo Vila Gonçalves Filho

Filiação institucional: Escola de Engenharia de São Carlos da Universidade de São Paulo (EESCUSP)

Departamento: Departamento de Engenharia Mecânica

Função ou cargo ocupado: Professor

Endereço completo para correspondência: Av. Trabalhador São Carlense, 400, Centro, São Carlos, SP, Brasil, CEP: 13566-590.

Telefones para contato: (016)

e-mail: evila@sc.usp.br

Recebido para publicação em: 15/10/2006

Aceito para publicação em: 19/01/2007 